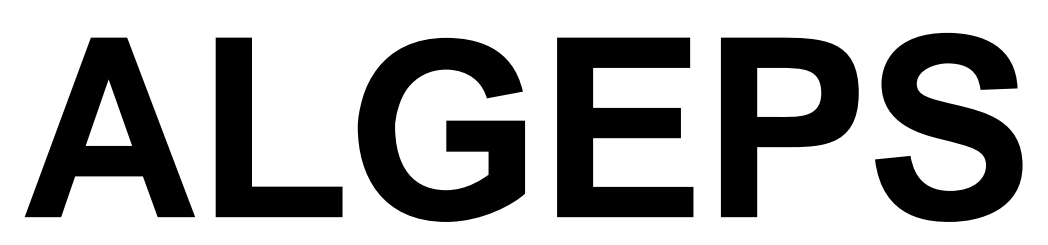

REVISTA DE GEOLOGIA, SÈRIE B no 628 - Abril del 2013

ISSN $1132-7014$

D.L.B. 28.178 - 92

14 pàgines

\title{
RECORREGUT GEOLÒGIC I MINERALÒGIC PER LA COMARCA DE LA TERRA ALTA: DES DE GANDESA A LA FONTCALDA, A PRAT DE COMPTE I A BOT
}

Josep M. Mata-Perelló i Joaquim Sanz Balagué 


\section{RECORREGUT GEOLÒGIC I MINERALÒGIC PER LA COMARCA DE LA TERRA ALTA: DES DE GANDESA A LA FONTCALDA, A PRAT DE COMPTE I A BOT}

Per Josep M. MATA-PERELLÓ i Joaquim SANZ BALAGUÉ

\section{ADVERTIMENTS PREVIS}

Com en altres recorreguts de RECERCA GEOLÒGICA I MINERALÒGICA ..., si es disposa del temps suficient, poden efectuar-se passant per totes les parades i filloles. En cas contrari, recomanem prescindir de les anomenades PARADES - CONDICIONALS.

També recomanem de cercar la informació més adient, sobre els trams a recórrer mitjançant camins de terra, o de pista. Precisament, en aquest itinerari, hi ha alguns trajectes d'aproximació cap a les mines, que haurem de fer per camins de terra en irregular estat de conservació.

Per d'altra banda, recomanem tenir una cura extrema de la NATURA, evitant qualsevol forma d'agressió sobre ella, o de fer-n'hi un mal ús del que en ofereix la nostra mare Terra.

\section{BREU INTRODUCCIÓ}

En aquesta ocasió, el recorregut del present itinerari discorrerà per una zona en la qual conflueixen tres unitats geològiques netament diferenciades: la Depressió Geològica de l'Ebre, la Serralada Prelitoral Catalana (del Sistema Mediterrani, com l'anterior), i la Serralada Ibèrica, tot i que en realitat es circularà quasi sempre per la denominada Zona d'Enllaç entre el Sistema Mediterrani i la Serralada Ibèrica.

Així, en els primers trams del recorregut, entre Gandesa i els voltants de les Mines de Sant Marc, el recorregut transitarà per la primera unitat geològica esmentada, (per la Depressió Geològica de l'Ebre), entre afloraments de materials cenozoics, generalment detrítics, de 1’Eocè i de 1’Oligocè.

Immediatament després, el recorregut transitarà per la zona de contacte entre la unitat geològica anterior i la Branca Externa de la Serralada Prelitoral, entre afloraments de materials mesozoics, entrant finalment dintre d'aquesta unitat geològica. En aquest recorregut, ens anirem apropant a la Serralada Ibèrica, sense deixar mai la denominada Zona d'Enllaç entre el Sistema Mediterrani i la Serralada Ibèrica. 
Així, aquests materials mesozoics s'aniran tallant fins arribar a Prat de Compte. Després, en anar cap a Bot, s'entrarà de nou a la Depressió Geològica de l'Ebre, per on finalitzarà el recorregut de l'itinerari.

Finalment, cal dir, que el recorregut de l'itinerari, discorrerà per una sola de les comarques, de la Regió de Tortosa; concretament per la de la Terra Alta.

\section{OBJECTIUS FONAMENTALS D’AQUEST ITINERARI}

Els objectius fonamentals que es pretenen aconseguir en aquest itinerari, es poden concretar en els següents aspectes generals:

1.- Observació i descripció dels materials terciaris (de l'Eocè i de l'Oligocè) de la Depressió Geològica de l'Ebre, que pertanyen majoritàriament al complex al-luvial de Gandesa - Horta de Sant Joan, que inclou, entre altres a la Formació Montsant i a la Formació Flix. Aquests materials, els veurem primer entre Gandesa i la Fontcalda, i després pels voltants de Prat de Compte, fins arribar a Bot. Cal dir que bona part d'aquesta zona, s'inclou dintre del denominat Avant-país, situat al contacte entre la Depressió Geològica de l’Ebre i la Serralada Ibèrica.

2.- Observació i descripció dels materials mesozoics (del Triàsic, del Juràssic i del Cretàcic) i dels cenozoics (de l'Eocè i de l'Oligocè), que constitueixen la Serralada Prelitoral Catalana. Aquests materials els trobarem a diferents indrets del recorregut de l'itinerari, especialment entre les Mines de Sant Marc i Prat de Compte.

3.- Observació de les estructures locals d'aquestes unitats geològiques acabades d'esmentar, que trobarem al llarg del recorregut de l'itinerari, i de les relacions existents entre elles. Així, ens referirem a les següents:

3A) a l'estructura de Branca Externa de la Serralada Prelitoral Catalana (integrant del Sistema Mediterrani), que trobarem a diferents trams del recorregut. En molts indrets, aquests es troben prop de la seva Zona d'Enllaç amb el Sistema Ibèric.

3B) de l'estructura de la Depressió Geològica de l'Ebre, que veurem als primers i als darrers trams del recorregut.

3C) de les relacions existents entre les unitats i sotsunitats geològiques acabades d'esmentar.

4.- Observació i reconeixement de diferents mineralitzacions situades a diferents indrets del recorregut de l'itinerari, (però sempre dintre de la Serralada Prelitoral Catalana), com són les següients:

4A) les mineralitzacions ferruginoses de rebliment de cavitats d'origen kàrstic, situades al terme de Gandesa (dintre de la comarca de la Terra Alta), entre els afloraments cretàcics.

4B) les relacionades amb les formacions argiloses, que trobarem a diversos indrets dels termes de Prat de Compte, ubicades entre els materials del trànsit del Cretàcic Superior al Paleocè, sempre dintre de la comarca de la Terra Alta.

5.- Observació de les antigues explotacions mineres relacionades amb les mineralitzacions anteriors. Al respecte, cal dir que totes elles es troben actualment aturades. 
6.- Observació i anàlisi dels impactes produïts sobre el Medi Natural (i sobre el Medi Ambient), tant per les explotacions mineres anteriors, com per altres activitats humanes.

7.- Observació dels diferents indrets relacionats amb el Patrimoni Geològic i Miner, que trobarem al llarg del recorregut. Entre aquests indrets, cal fer esment, entre altres dels paratges de les Gúbies del Riu Canaletes, prop de la Fontcalda, entre Gandesa i Prat de Compte.

\section{ANTECEDENTS BIBLIOGRÀFICS}

Pel que fa al recorregut del present itinerari, existeixen alguns antecedents molt propers, obra del mateix autor del present itinerari. Es tracta de MATA-PERELLÓ (1996b, 1997, 2000a, 2000b, 2001a, 2001b i 2005). Un altre antecedent parcial, obra del mateix autor, es troba a MATA-PERELLÓ (1989), i correspon a un altre itinerari. Tanmateix, cal fer esment del treball de MATA-PERELLÓ i MONTANÉ GARCÍA (2006), en un itinerari fora semblant al present. Tanmateix, farem esment d'un altre treball nostre: MATA-PERELLÓ et altre (2006).

Pel que fa a la descripció de les mineralitzacions d'aquesta comarca, farem esment d'un altre treball del mateix autor, de MATA-PERELLÓ (1991), relatiu a les mineralitzacions catalanes en general. Uns altres antecedents, cal situar-los en MATAPERELLÓ (1995a i 1995b), relatius als inventaris mineralògics de les comarques de la Terra Alta i del Matarranya.

I, finalment, pel que fa a l'estructura geològica de la zona per la qual discorre l'itinerari, farem esment dels treballs de GUIMERÀ et altri (1982) i de RIBA et altri (1976). També, i dintre d'aquest apartat, també farem esment de diversos treballs de l'IGME (1972). Tots ells són relatius a diversos fulls geològics corresponents als indrets per on passarà el recorregut de l'itinerari.

Tots aquests treballs referenciats, i d'altres, figuren esmentats per ordre alfabètic a l'apartat dedicat a la BIBLIOGRAFIA.

\section{RECORREGUT DE L'ITINERARI}

El recorregut de l'itinerari començarà dintre de la comarca de la Terra Alta, concretament a Gandesa, la seva capital, des de la qual s’anirà cap a les Mines de Sant Marc i cap al Santuari de la Fontcalda, per on es faran diferents aturades. En aquest recorregut es farà una fillola, per tal d'anar a l'ermita de Santa Magdalena, per on es farà una aturada.

Després, el recorregut es dirigirà cap als voltants de Prat de Comte, per on es faran noves aturades. A continuació, el recorregut es dirigirà cap a les immediacions de la població de Bot, per on s'efectuaran noves aturades, finalitzant el recorregut. 


\section{DESCRIPCIÓ DE L'ITINERARI}

Com de costum, estructurarem el recorregut de l'itinerari en una sèrie de PARADES, que tot seguit anirem veient. En cada una d'aquestes aturades farem un breu comentari (geològic o mineralògic, segons s'escaigui).

Cada una d'aquestes parades tindrà un número, i un topònim representatiu. Per d'altra banda, s'indicarà el nom del poble més proper, el municipi al qual pertany l'indret, $\mathrm{i}$ la comarca on es troba situat. Per d'altra banda, també indicarem en cada cas, i entre parèntesi, el full topogràfic on es troba l'aturada.

Finalment, cal dir que el recorregut de l'itinerari s'inclourà dintre dels següents fulls, del "Mapa Topográfico Nacional", realitzats a l'escala 1:50.000 per 1'"Instituto Geográfico y Catastral": 470 (dit de Gandesa) i 496 (dit d'Horta de Sant Joan).

Així doncs, la relació de parades ordenades, que composen aquest itinerari geològic i mineralògic, és el següent:

\section{PARADA 1- CONDICIONAL. ESTACIÓ D'AUTOBUSOS, (terme municipal de Gandesa, comarca de la Terra Alta). (Full 470).}

El recorregut del present itinerari, s'iniciarà a la població de Gandesa, la capital de la comarca de la Terra Alta, iniciant-se prop de la moderna Estació d'Autobusos de la població, la qual es troba tot sortint cap a Corbera de Terra Alta, junt al costat de la carretera N-420 (la Còrdova - Tarragona).

Al respecte, cal dir que tant la població, com bona part del seu terme, es troba situat a la Depressió Geològica de 1'Ebre, molt a prop del contacte amb la Serralada Prelitoral, per la denominada Zona d'Enllaç amb el Sistema Ibèric. També cal recordar que l'esmentada serralada es troba al SE, al Sud $i$ al SW d'on som, i es troba constituta pels relleus mesozoics de la Serra de Cavalls i els de la Serra de Pàndols.

Així, els materials que es troben en aquest indret són terciaris, $i$ més concretament de l'Oligocè. Pertanyen, per d'altra banda, a la Formació Flix, que aquí forma part del Complex al.luvial de Gandesa - Horta de Sant Joan.

Els afloraments d'aquesta formació, es troben constituïts per nivells de calcolutites ocres $i$ de gresos, del mateix color, clarament continentals. Afloren amplament al Nord $i$ al NE de Gandesa. Per d'altra banda, també cal dir que sovint, entre aquests materials es fan palesos paleocanals, com veurem més endavant prop de Bot.

PARADA 2 - CONDICIONAL. COLLET DE GANDESA, (terme municipal de Gandesa, comarca de la Terra Alta). (Full 470).

Després de fer l'aturada anterior, es pot fer un petit recorregut (de quasi 2'5 Km) per la carretera C-12B, amb la intenció d'arribar fins al Collet de Gandesa. Aquí farem, si s'escau, una nova aturada. 
En el recorregut, des de la parada anterior, s'ha anat trobant els materials cenozoics de la Depressió Geològica de l'Ebre. Tot i així, ara s'han començat a trobar nivells de materials carbonatats mesozoics, els quals formen part de la Serralada Prelitoral Catalana, on ara hem arribat. És as dir, ara ens trobem a la zona de contacte entre les dues unitats geològiques esmentades.

PARADA 3. TRENCALL DEL SINCLINAL DE SANT MARC, (terme municipal de Gandesa, comarca de la Terra Alta). (Full 470).

Des de la parada anterior, cal seguir per la carretera C-45B, (fins fa poc anomenada C-235), la qual es dirigeix cap a Pinell de Brai. Tot i així, poc després de trobar el trencall de la Fontcalda, es trobarà a l'esquerra de la carretera un tram antic de la mateixa, on ens caldrà aparcar. Per aquest indret, farem una nova aturada, després de recórrer Així, uns 2 $\mathrm{Km}$, des del Collet de Gandesa.

Aquest recorregut, inicialment 1 'hem fet pels materials cenozoics esmentats a la parada anterior. Tot i així, ben aviat haurem entrat a la Serralada Prelitoral (i més exactament a la seva Branca Externa) i haurem començat a trobar afloraments dels materials mesozoics, del Juràssic i del Cretàcic, similars al que ara trobem a l'indret on fem aquesta parada.

Cal dir que aquests materials es troben força replegats. Així, al mateix indret de l'aturada es pot veure un interessant sinclinal. Precisament la carretera i un torrentet, es troben al seu nucli. Un esquema d'aquest sinclinal, és el següent:

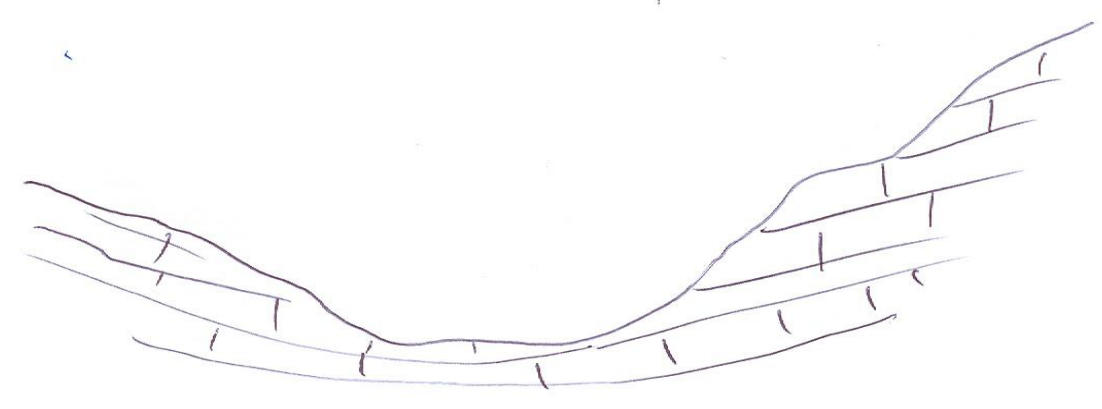

PARADA 4. MINES DE FERRO DE SANT MARC, (terme municipal de Gandesa, comarca de la Terra Alta). (Full 470).

Desprès de fer l'aturada anterior, cal recórrer uns $100 \mathrm{~m}$, tot tirant a peu endarrere per la carretera, fins arribar a un caminet, que en uns altres $100 \mathrm{~m}$, arriba fins a les Mines de Ferro de Sant Marc, Aquí farem una nova aturada.

En aquest breu recorregut, haurem anat trobant els materials esmentats a la parada anterior, aquests es troben força fracturats. Més endavant, a l'indret de l'aturada, sobre els nivells carbonatats, pot veure's com s'han desenvolupat unes interessants mineralitzacions ferruginoses associades a rebliments kàrstics. FOTOGRAFIES 1 i 2 
Entre els minerals presents, cal fer esment de la presència d'HEMATITES (molt abundant a les boques superiors), i de GOETHITA (en forma de LIMONITA, molt abundant a les inferiors). També és molt abundant la CALCITA.

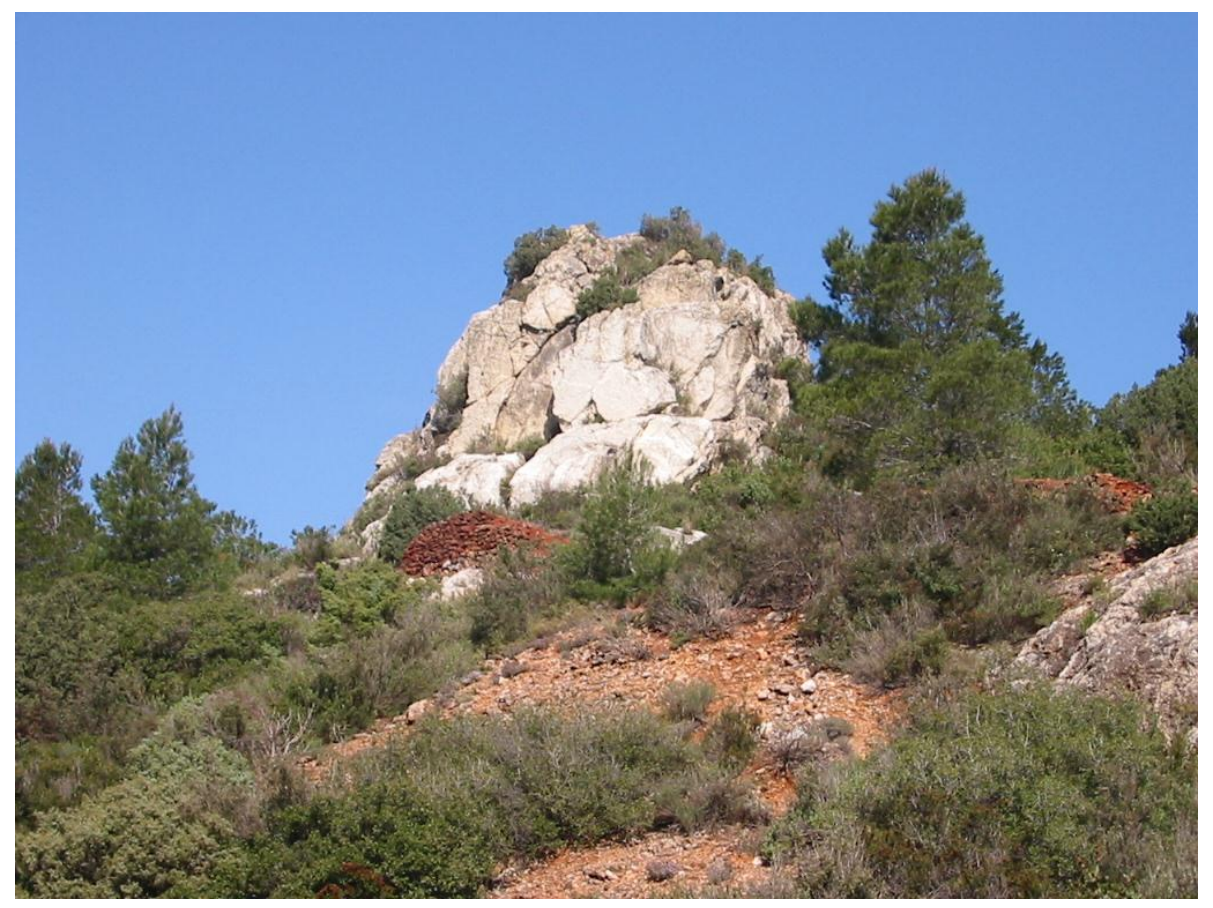

FOTOGRAFIA 1

Detall de les escombreres de les Mines de Ferro de Sant Marc

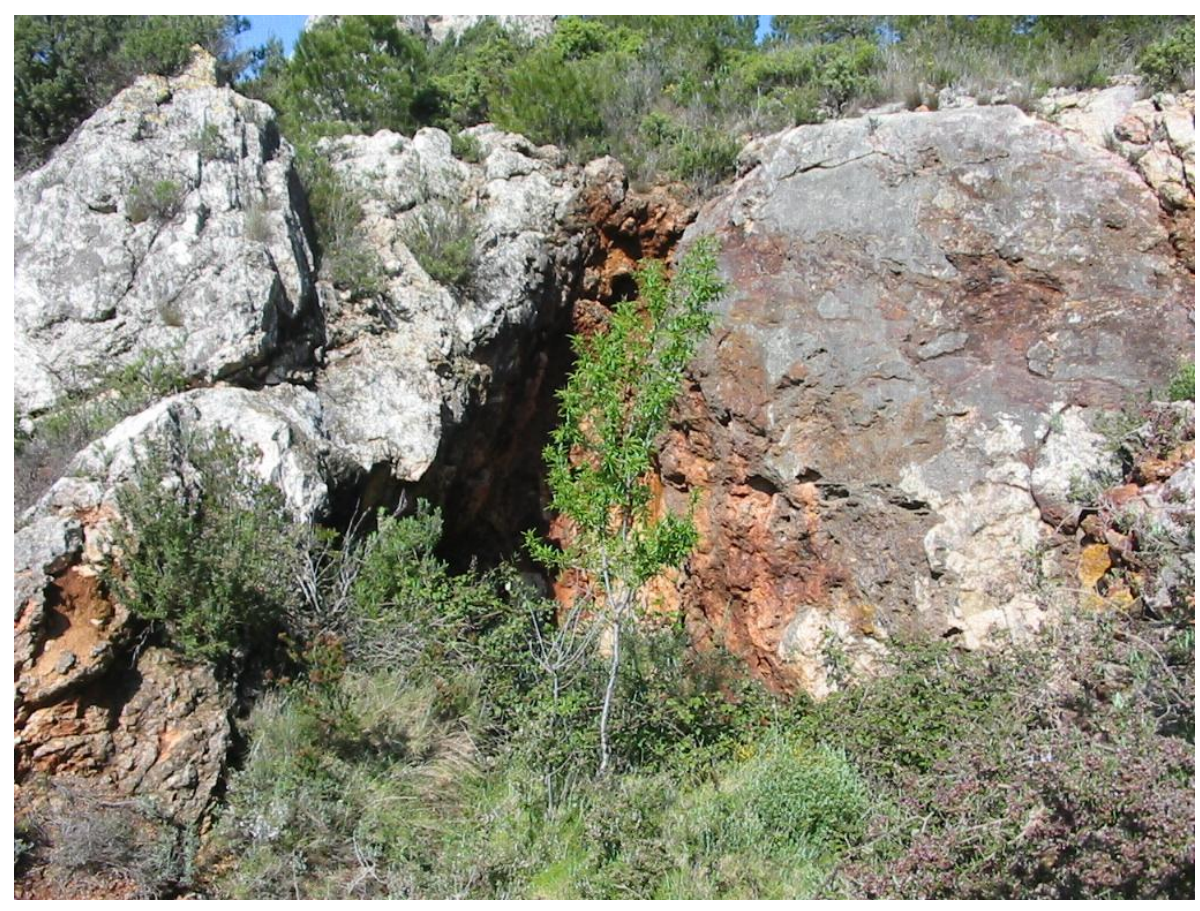

FOTOGRAFÍA 2

Detall de la mineralització 
Car fer esment de que aquests materials es van intentar explotar mitjançant una mina. A l'actualitat encara es possible de veure un pouet, i sobre tot l'escombrera roja. Molt palesa des de la propera carretera.

PARADA 5. ERMITA DE SANTA MAGDALENA, (terme municipal del Pinell de Brai, comarca de la Terra Alta). (Full 470).

Des de la parada anterior, cal agafar la carretereta que condueix cap al Santuari de la Fontcalda. Després d'un recorregut proper als $2 \mathrm{Km}$ arribarem a una cruïlla d'on eix un camí de terra (en bon estat i prou ample), el qual condueix cap a l'Ermita de Santa Magdalena. Aquí, després d'un camí ascendent de quasi $4 \mathrm{Km}$, a $6 \mathrm{Km}$ de la parada anterior, en farem una altra.

Després de la parada anterior, i sobretot en aquest lloc, s' han continuat trobant els nivells carbonatats, que pertanyen al Cretàcic. Aquests materials, pertanyen a la Serralada Prelitoral Catalana, i més exactament al conjunt de la Serra de Pàndols-Serra de Cavalls, on ens trobem ara situats.

Des d'aquest indret, en dies clars, es possible fer una interessant aturada d'observació general. En efecte, des d'aquí, es pot gaudir d'una bona observació de la Serralada Prelitoral, entre els voltants de Colldejou i el Bloc de Cardó. Tanmateix es pot veure el Delta de l'Ebre. Mirant cap al Nord i cap al NE, es pot veure la zona ocupada per la Depressió Geològica de l'Ebre. I tanmateix, en dies molt clars, es poden veure fins i tot els Pirineus.

Més a prop, mirant cap a Pinell de Brai, al Sud i SE d'on ara som, es pot veure la interessant discordança de l'Estació de Brai. Prop d'aquesta, per d'altra banda, es poden veure les explotacions de les argiles del Danià.

PARADA 6 - CONDICIONAL. MINETA DE FERRO DE LA FONTCALDA, (la Fontcalda, terme municipal de Gandesa, comarca de la Terra Alta). (Full 470).

Des de la parada anterior, cal retornar cap a la carretereta que condueix cap al Santuari de la Fontcalda. Després d'un recorregut proper als $4 \mathrm{Km}$, arribarem a l'indret de la present aturada.

Després de la parada anterior, $i$ sobretot en aquest lloc, $s$ 'han continuat trobant els nivells carbonatats, que pertanyen al Cretàcic. Aquests materials, pertanyen a la Serralada Prelitoral, $i$ més exactament al conjunt de la Serra de Pàndols-Serra de Cavalls. Aquests nivells calcaris es troben en contacte amb altres d'argilosos $i$ guixosos, que pertanyen al Triàsic Superior (al Keuper). Per d'altra banda, sempre hem circulat prop del contacte entre aquests materials i els oligocènics de la Formació Montsant, els quals pertanyen a la Depressió Geològica de 1'Ebre, la qual s'estén cap a ponent d'on ara som. Precisament, a l'aturada següent, i fins $i$ tot d'aquest indret, $i$ mirant cap al NNW es pot veure una bona perspectiva de l'esmentada depressió. 
Per d'altra banda $i$ sobre els nivells calcaris, es troba una mineralització ferruginosa de rebliment de cavitats kàrstiques. Entre els minerals presents, predomina el la GOETHITA (sempre en forma de LIMONITA), que es troba acompanyada d'indicis d'HEMATITES i de SIDERITA. També hi ha CALCITA, la qual és molt abundant.

PARADA 7. COLLET DE LA FONTCALDA, (la Fontcalda, terme municipal de Gandesa, comarca de la Terra Alta). (Full 470).

Des de la parada cal continuar per la carretereta que es dirigeix cap al Santuari de la Fontcalda. Després d'un recorregut proper als 0’5 Km, arribarem a un indret on la ruta passa cap a l'altra banda de la serra, just on hi ha unes antigues explotacions de calcaries. Aquí farem una nova aturada.

En aquest curt recorregut, hem anat trobant els materials mesozoics esmentats a la parada anterior.

En aquest indret, mirant cap al NW es pot veure una interessant instantània del contacte entre la Serralada Prelitoral Catalana i la Depressió Geològica de l’Ebre. Per d'altra banda, entre els materials cenozoics que constitueixen aquesta darrera, es pot veure la interessant discordança progressiva de Bot - Horta de Sant Joan. Això és: (FOTOGRAFIA 3).

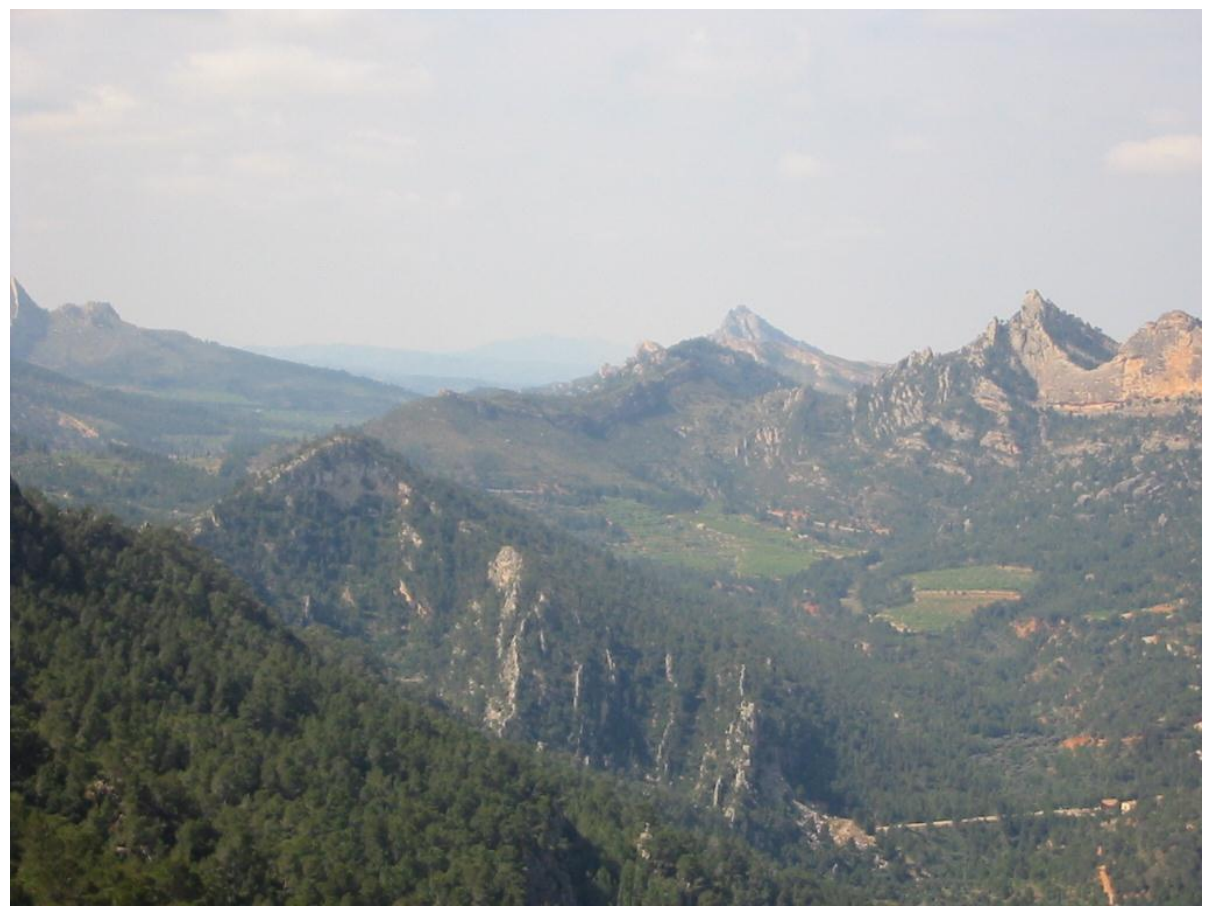

FOTOGRAFIA 3

Contacto entre la Serralada Prelitoral Catalana i la Depressió Geològica de l’Ebre Discordança progressiva de Bot - Horta de Sant Joan 
PARADA 8. SANTUARI DE LA FONTCALDA, LA FONTCALDA, (terme municipal de Gandesa, comarca de la Terra Alta). (Full 470).

Des de la parada anterior, cal continuar per la carretereta que es dirigeix cap al proper Santuari de la Fontcalda (el qual es troba a la vora del riu Canaleta) on realitzarem la present aturada, després de recórrer uns $3 \mathrm{Km}$, des de la parada anterior, sempre per la vora del riu.

Des de la parada anterior, la carretereta va circulant sempre prop del contacte esmentat a la parada anterior. Tot i això, sempre es troba dintre de la Serralada Prelitoral Catalana. En aquest recorregut, en iniciar el descens, haurem trobat un interessant mirall de falla en una de les primeres corbes. Es tracta d'una de les nombroses falles que fan trencant els materials de la serralada.

En arribar a l'indret de l'aturada, en un lloc d'immillorable bellesa, el qual es troba al mateix contacte per falla entre els materials terciaris de la Depressió Geològica de l'Ebre, els quals pertanyen a la Formació Montsant (que aquí són més lutítics), i els nivells carbonatats cretàcics, de la Serralada Prelitoral Catalana del Sistema Mediterrani.

Cal fer esment, de que els primers materials esmentats es troben en una clara posició vertical, donant lloc a interessants formes erosives, per la diferència entre els trams calcolutítics i els detrítics.

Prop del Santuari, es troba la coneguda Fontcalda, que dona nom a l'indret. Es tracta d'una interessant surgència d'aigua calenta (a uns $20^{\mathrm{a}} \mathrm{C}$ ), que aprofita una de les nombroses fractures.

PARADA 9. LES GUBIES DEL RIU CANALETA, (termes municipals de Gandesa, Bot i Prat de Compte, comarca de la Terra Alta). (Full 470).

Després de fer l'aturada anterior, cal fer un breu recorregut a peu, remuntant el riu Canaleta. A menys de 0`2 Km caldrà fer una nova aturada.

En arribar a l'indret de l'aturada, s'han continuat trobant els materials esmentats a la parada anterior. Així es fan palesos els nivells calcaris del Cretàcic, que es troben verticalitzats. FOTOGRAFIA 4.

El riu, en travessar-los, va fent freqüents saltants, de gran bellesa. Al final de l'estret (o de les Gúbies), es troba el contacte discordant entre els nivells mesozoics i els terciaris detrítics de la Formació Montsant, que constitueixen la Serra del Puig Cavaller. FOTOGRAFIA 5.

PARADA 10. EXPLOTACIONS LUTÍTIQUES DE PRAT DE COMPTE, (terme municipal de Prat de Compte, comarca de la Terra Alta). (Full 496).

Des de la parada anterior, cal passar a l'altra banda del riu, si es pot. Tot seguit, cal anar cap al poble Prat de Compte. Més endavant en arribar-hi, ens caldrà seguir per la 
carretera local T-330 (la qual se'n va cap a Horta de Sant Joan). Justament, des d'aquesta carretera, a la sortida de Prat de Compte, s'accedeix directament a les explotacions lutítiques del Barranc de la Xalamera, on farem la present aturada després de recórrer uns 7-8 Km des de la parada anterior, i menys de 1'5 Km des del poble.

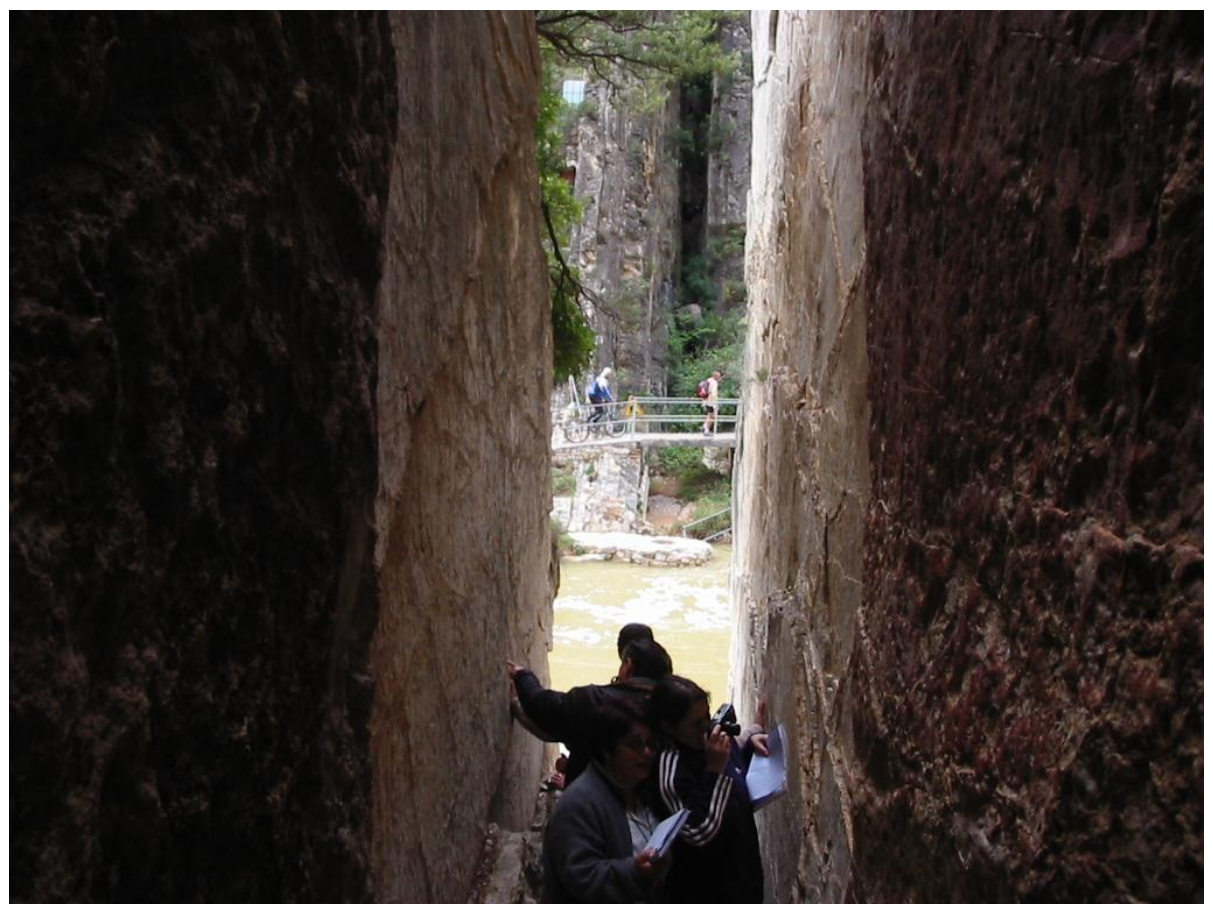

FOTOGRAFIA 4

Un aspecte de les Gúbies. Escletxa

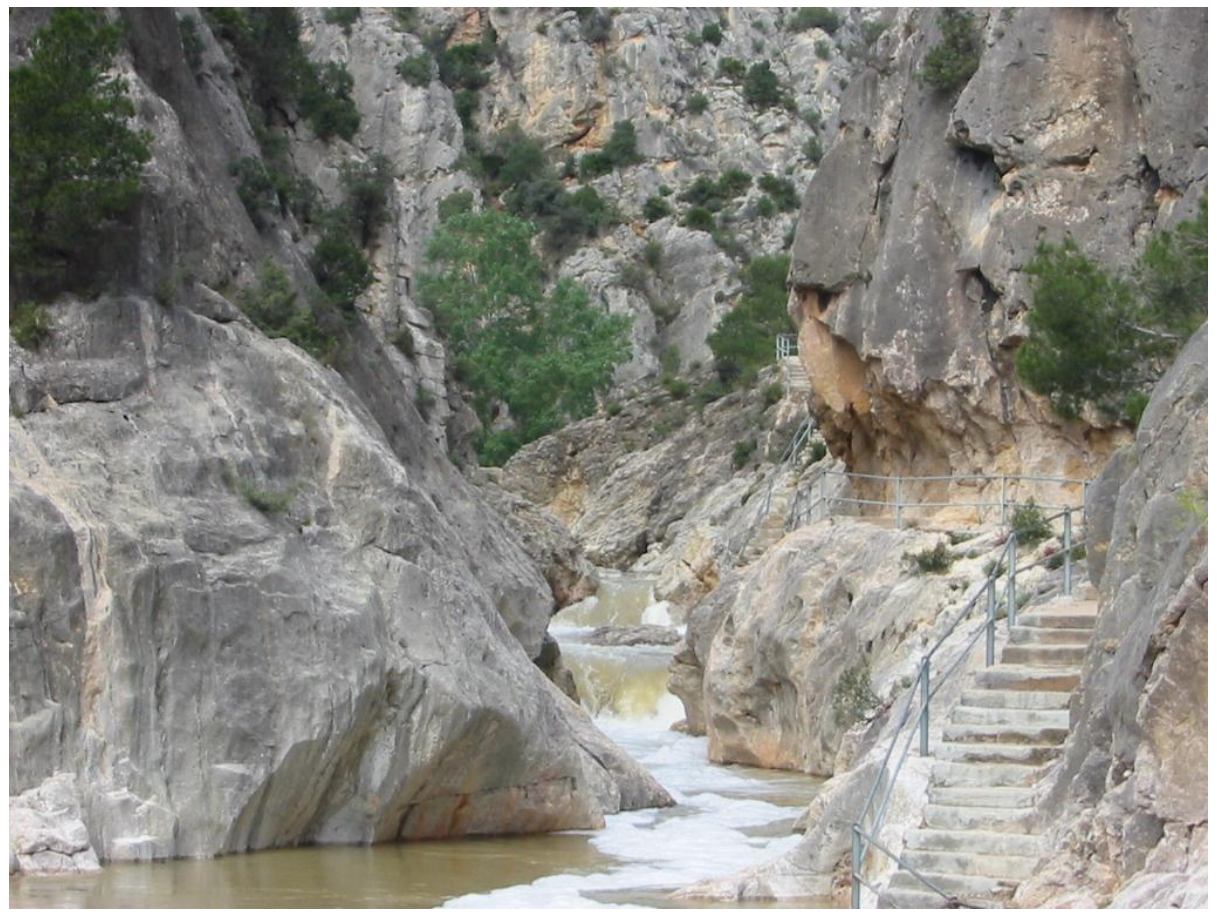

FOTOGRAFIA 5

Un aspecte de les Gúbies 
En aquest recorregut, hem tornat a tallar la sèrie, tot i que sovint hem transitat per prop del contacte Cretàcic-Paleocè. Així, sovint hem tallat afloraments dels materials mesozoics (del Triàsic, Juràssic i Cretàcic), així com dels cenozoics (del Burdigalià). Tots ells formen part de la Serralada Prelitoral Catalana.

En aquest lloc hi ha una explotació d'uns nivells lutítics, que pertanyen al trànsit del Cretàcic Superior a l'Eocè. Aquests materials pertanyen a la Serralada Prelitoral Catalana del Sistema Mediterrani, on ens trobem ara situats.

Entre aquests nivells, que aquí són molt sorrencs, es troba una abundant presència d'HEMATITES, i naturalment de CAOLINITA, que és el mineral explotat. També cal fer esment de la presència de QUARS (en forma d'arena).

Cal dir, per d'altra banda, que a més a més d'aquesta explotació de materials refractaris, n'existeixen d'altres, situades a diferents indrets del terme de Prat de Compte, i ubicades sempre entre aquests mateixos materials.

PARADA 11. L'AGULLA DE BOT, (terme municipal de Bot, comarca de la Terra Alta). (Full 496).

Des de la parada anterior, cal continuar per la carretera local que es dirigeix cap a Bot. Així, després d'un recorregut d'uns $7-8 \mathrm{Km}$, arribarem a les immediacions de l'indret on podem veure l'Agulla de Bot. En aquest indret farem una nova aturada, la darrera d'aquest recorregut.

En aquest tram del recorregut de l'itinerari, haurem trobat afloraments dels materials detrítics cenozoics, que formen part de la Depressió Geològica de l'Ebre, on estem ara situats.

Des d'aquí, es pot veure la denominada Agulla de Bot. Es tracta d'un relleu desenvolupat sobre els materials detrítics, que hem esmentat al paràgraf anterior. Cal dir que aquest relleu es observat des de molts indrets de les comarques veïnes.

\section{EN AQUEST INDRET FINALITZA L'ITINERARI}

\section{REFERÈNCIES BIBLIOGRÀFIQUES}

GUIMERÀ, J. et altri (1992).- Geologia (II), Història Natural dels Països Catalans, Vol.2, 547 pag. Enciclopèdia Catalana, S.A. Barcelona

IGME (1974).- Mapa Geológico de España a escala 1:200.000. Sintesis de la Cartografia existente. Hoja y memória nº 41 (Tortosa). Inst. Geol. Min. España. Minist. Indústria. Madrid

MATA-PERELLÓ, J.M. (1989).- Una recerca mineralògica per les terres de 1'Ebre: del Matarranya al Priorat. But. Col. Ofi, de Doctors i Llicenciats, nº 67, 15pag. Barcelona 
MATA-PERELLÓ, J.M. (1991).- Els Minerals de Catalunya. Arxius de la Secció de Ciències, t. XCIII, 442 pag. Institut d'Estudis Catalans. Barcelona

MATA-PERELLÓ, J.M. (1995a).- Inventari Mineralògic de la comarca de la Ribera d’Ebre, Terra Endins, n 9, 23 pag. Manresa

MATA-PERELLÓ, J.M. (1995b).- Inventari Mineralògic de la comarca de la Terra Alta, Terra Endins, n ${ }^{\circ}$ 10, 22 pag. Manresa

MATA-PERELLÓ, J.M. (1996).- Itinerari geològic i mineralògic entre Gandesa, la Fontcalda i Vall-de -roures. Inèdit., 12 pàgines. Manresa

MATA-PERELLÓ. J.M. (1997).- Recerca geològica i mineralògica per les comarques de la Terra Alta i del Matarranya: des de Gandesa a Bot i Horta de Sant Joan, i des de Vallde-roures a Fondespatlla. Inèdit, 17 pàg. Manresa

MATA-PERELLÓ. J.M. (2000a).- Recerca geològica i mineralògica per les comarques de la Terra Alta i de la Ribera de 1'Ebre: des de Pinell de Brai i Prat de Compte a Gandesa i a Mora d'Ebre. Algeps, sèrie B, no 171, 14 pàg. Manresa

MATA-PERELLÓ. J.M. (2000b).- Recerca geològica i mineralògica per les comarques de la Terra Alta i del Matarranya: des de Gandesa a Vall-de-roures i a Fondespatlla. Algeps, sèrie $B, \mathrm{n}^{\circ} 176,18$ pàg. Manresa

MATA-PERELLÓ. J.M. (2001a).- Recorregut de recerca geològica i mineralògica per les comarques de la Ribera d'Ebre i de la Terra Alta: des d'Ascó a Pinell de Brai, i des de Prat de Compte a Horta de Sant Joan, Inèdit, 18 pàg. Manresa

MATA-PERELLÓ. J.M. (2001b).- Recorregut de recerca geològica i mineralògica per les comarques de la Terra Alta i del Matarranya: des d'Horta de Sant Joan a Vall-de-roures i a Fontespatlla Inèdit, 18 pàg. Manresa

MATA-PERELLÓ, J.M. (2005).- Recorreguts per la comarca de la Terra Alta: des del Pinell de Brai, a Prat de Compte i a Horta de Sant Joan. Inèdit. 12pag. Manresa

MATA-PERELLÓ. J.M. i HERRERA SANCHO, J.A. (2001).- Recorregut de recerca geològica, mineralògica i naturalístiques pels Ports Inèdit, 18 pàg. Manresa

MATA-PERELLÓ, J.M. i MONTANÉ GARCÍA, P. (2006).- Recorregut geològic i mineralògic per la comarca de la Terra Alta: des de Gandesa a Prat de Compte, a Horta de Sant Joan i a Arnés. Inèdit, 12 pag. Manresa

MATA-PERELLÓ, J.M.; MONTANÉ GARCÍA, P. i CARDONA GAVALDÀ, V. (2006).- Recorregut geològic i mineralògic per la comarca de la Terra Alta: des de Gandesa a la Fontcalda, Prat de Compte, Horta de Sant Joan, Arnés i Val-de-roures. Inèdit, 14 pag. Manresa

RIBA, O. et altri (1976).- Geografia Física dels Països Catalans, Edit. Ketres, 254 pàgines. Barcelona. 